\title{
Relationship between cotinine levels, household and personal smoking habit and season in 9-14 year old children
}

\author{
R. Ronchetti, E. Bonci, G. de Castro, F. Signoretti, F. Macri', G.C. Ciofetta, \\ M.P. Villa, L. Indinnimeo, F.D. Martinez*
}

Relationship between cotinine levels, household and personal smoking habit and season in 9-14 year old children. R. Ronchetti, E. Bonci, G. de Castro, F. Signoretti, F. Macri', G.C. Ciofetta, M.P. Villa, L. Indinnimeo, F.D. Martinez. CERS Journals Ltd 1994.

ABSTRACT: The aim of this study was to determine the relationship of salivary cotinine levels with individual and household smoking habits and with the season in a sample ( $n=146)$ of Italian schoolchildren aged 9-14 yrs.

Active smoking and environmental tobacco smoke were measured by means of a confidential standardized interview with each participating child and by a selfreported questionnaire administered to the parents. Saliva samples were obtained twice: during winter from all children and during spring from a randomly selected subgroup.

"Active smokers" were significantly more likely to be males and to live with smoking family members. Frequency of detectable cotinine both in "nonsmokers" and "active smokers" was significantly correlated with the number of cigarettes smoked by household members. However, for any level of smoking by parents detectable cotinine was more likely to be found in "active smokers" than in "nonsmokers". In "nonsmokers", the proportion of subjects with detectable cotinine decreased significantly in spring compared to winter, a finding not observed in "active smokers".

In conclusion, we have demonstrated that passive smoking produces most effect in winter, and is linked to the amount and style of the parents' smoking, mainly related to smoking in presence of children. Conversely, salivary cotinine detected in spring appears to be derived mainly from active smoking.

Eur Respir J, 1994, 7, 472-476.
IV Cattedra di Clinica Pediatrica, University "La Sapienza", Rome, Italy. *Dept of Pediatrics, Arizona Health Science Center, Tucson, USA.

Correspondence: R. Ronchetti IV Cattedra di Clinica Pediatrica Universita' "La Sapienza"

Viale Regina Elena 324

00164 Rome

Italy

Keywords: Cotinine

smoking habit

season

children

Received: February 31993

Accepted after revision October 31993

Supported in part by grants from the Progetto Finalizzato Medicina Preventiva, Subprogetto Medicina Perinatale, Consiglio Nazionale delle Ricerche.
Many studies have established a significant causal relationship between passive smoking exposure and ill health in children $[1,2]$. In particular, most of the evidence suggests that there is a qualitative relationship between environmental tobacco smoke exposure (ETS) and negative consequences for the child [2-9]. However, some studies have found little or no effect $[10,11]$, and the dose-effect balance is incompletely defined and understood so far.

A quantitative approach to this relationship requires a knowledge of the magnitude of exposure, which can be assessed by determining the level of a metabolite sufficiently long-lived in the organism, only derived from smoke inhalation and easily measured in body fluids. Determination of cotinine levels in body fluids has definitely improved the study of the degree of tobacco smoke absorption by exposed subjects in large population samples.

However, there are many other requirements for better quantitative assessment of dose-effect relationships. Whilst some investigators have defined passive smoking by determining the number of cigarettes smoked daily by parents, many others have simply classified household smoking patterns as either presence or absence of smoking by both parents. Obviously, it should be clear whether parents smoke inside or outside the home; furthermore, the existence of the multiple or intermittent sources of passive smoke exposure for the child should be properly defined. The effect of season (higher level of indoor cigarette smoke in winter) has sometime been suspected but not proved [12]. After a certain age, the matter is further complicated by the child's active smoking, because even as little as one cigarette a week is equivalent to more nicotine that can be absorbed by means of passive exposure.

Several recent reports have used cotinine levels to study the factors that increase exposure to ETS and its absorption in early childhood [13], but very few studies have addressed these same issues in older children [14]. The aim of this study was to determine, in a sample of Italian schoolchildren, the relationship of salivary cotinine levels with smoking amount and pattern of household 
members; also taking into account the contribution of children actively smoking, explored by means of a confidential questionnaire; and of the season, by measuring salivary cotinine in two different meterological conditions.

\section{Subjects and methods}

The subjects were selected from a larger sample of children aged 9-14 yrs in the Viterbo province near Rome. Originally, a questionnaire concerning mainly parental smoking habits was distributed to all 1,430 children aged 9-14 yrs, who were pupils of public schools. A total of $1,208(86 \%)$ returned the questionnaires. Using these questionnaires, the population was divided into smoking and nonsmoking households, i.e. those in which no household member smoked and those in which at least one household member smoked cigarettes. Each group was further subdivided according to the child's gender and a random sample of 188 children was obtained from the four resulting subgroups. The parents of the children selected were contacted and requested to take part in the study. A total of 146 accepted; a participation rate of $78 \%$. The nonresponse group was not different for sex, age and social economic conditions.

Standardized questions on respiratory symptoms were used to eliminate subjects with asthma, recurrent wheeze or chronic cough. A crowding index (number of rooms per person) and availability of central heating were used as indices of standard of living. A second, detailed questionnaire on smoking behaviour by household members was administered to one parent by a well-trained medical member of our team. Parents were asked about the number of cigarettes smoked, and whether they were smoked whilst at home. Specifically, they were asked if they smoked $>4$ cigarettes-day ${ }^{-1}$ "at the dinner table" or "in the television room after dinner". In addition to the parental questionnaire, each participating child was interviewed privately, after assuring her/him of the confidentiality of the interview. Specifically, the child was asked: "Have you ever tried to smoke cigarettes"? If they answered affirmatively, they were asked if this had happened "once or twice ever", "seldom", or "at least once a week". An additional question asked the child to specify the number of cigarettes smoked per week or per day and their opinion about smoking.

Saliva samples were obtained from all children during the second half of February and the first half of March 1987, between 9 and 11 am.

A second saliva sample was obtained from a randomly selected subgroup of 69 (47\%) of these children during the first half of June 1987. All saliva samples were coded, immediately frozen, and shipped to the American Health Foundation in Valhalla, New York, USA. The laboratories were blind to all information about the subjects and their parents' smoking habits. Cotinine was measured by a modified radioimmunoassay, as originally described by LANGONE et al. [15]. Children were considered "active smokers" if they acknowledged ever having tried to smoke cigarettes and "nonsmokers" otherwise. In addition, six subjects who said that they were nonsmokers but who had cotinine levels of $\geq 11$ $\mathrm{ng} \cdot \mathrm{ml}^{-1}$ were excluded from the analyses. This decision was based on a cut-off of $11 \mathrm{ng} \cdot \mathrm{ml}^{-1}$, as previously defined by JARVIS et al. [16] to distinguish active from passive smoking. This may have excluded children who were heavily exposed to ETS but did not smoke themselves. However, our conservative approach makes possible confounding of results by active smoking very unlikely.

\section{Data analysis}

In view of the skewed nature of the distribution for salivary cotinine concentration, geometric means were calculated. For logarithmic transformation, no detectable cotinine concentrations were assigned a value of $0.5 \mathrm{ng} \cdot \mathrm{ml}^{-1}[14]$.

In order to compare cotinine levels and smoking behaviour in the household, Kendall's Tau was used as a test of non parametric correlation. Chi-squared was used to compare proportions. McNemar's test was used to assess changes in the proportion of subjects with detectable cotinine between winter and spring.

Logistic regressions were carried out to compare "active smokers" with "nonsmokers" after controlling for other variables (sex, housing, heating, smoking by parents).

Statistical significance was defined as a $\mathrm{p}<0.05$ with use of a two-tailed distribution, and the SPSS-PC+ software for the IBM-PC/AT was used in the statistical analyses [17].

\section{Results}

Table 1 shows the characteristics of "active smokers" and "nonsmokers" (as defined in Methods). Among the 37 subjects who admitted smoking experiences, only four subjects smoked regularly: one subject smoked

Table 1. - Characteristics of the subjects studied

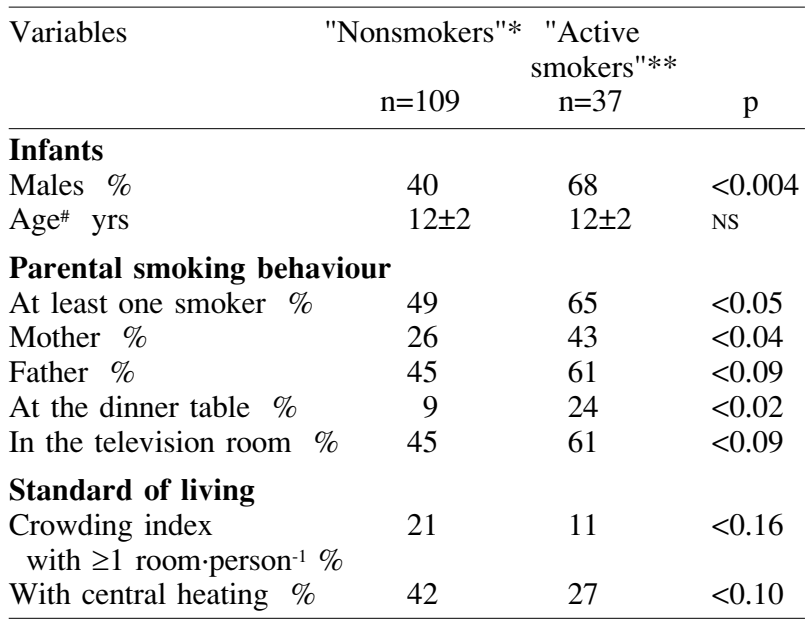

*: children with cotinine level $\leq 10 \mathrm{ng} \cdot \mathrm{ml}^{-1}$ and who denied smoking experiences; ${ }^{* *}$ : children who admitted smoking experiences; \#: mean \pm SD. NS: nonsignificant. 
Table 2. - Relationship between cotinine and number of cigarettes smoked by household members (measured during winter period)

\begin{tabular}{|c|c|c|c|c|c|}
\hline & \multicolumn{5}{|c|}{ Cigarettes smoked in household $n$} \\
\hline & 0 & $1-19$ & $20-39$ & $>40$ & $\mathrm{p}$ \\
\hline \multicolumn{6}{|l|}{ "Nonsmokers" } \\
\hline Subjects with cotinine $\%$ & 14 & 10 & 24 & 67 & $<0.0001$ \\
\hline Concentration $^{\dagger *} \mathrm{ng} \cdot \mathrm{ml}^{-1}$ & 0.66 & 0.66 & 0.91 & 1.77 & $<0.0001$ \\
\hline Total $\mathrm{n}$ & 56 & 10 & 17 & 26 & \\
\hline \multicolumn{6}{|l|}{ "Active smokers" } \\
\hline Subjects with cotinine $\%$ & 23 & 33 & 83 & 67 & $<0.0001$ \\
\hline Concentration $^{\# *} \mathrm{ng} \cdot \mathrm{ml}^{-1}$ & 0.78 & 1.68 & 3.02 & 4.26 & $<0.0001$ \\
\hline Total $\mathrm{n}$ & 13 & 3 & 12 & 9 & \\
\hline
\end{tabular}

: geometric mean data from all subjects in group; *: undetectable cotinine concentrations were recorded as $0.5 \mathrm{ng} \cdot \mathrm{ml}^{-1}$. To convert values to nmoles $\cdot l^{-1}$ multiply by 5.682 .

1 cigarette $\cdot$ week $^{-1}$, two smoked 1 cigarette $\cdot$ day $^{-1}$ and one smoked 5-8 cigarettes.day ${ }^{-1}$ (data not shown). "Active smokers" were significantly more likely to be males and to live with smoking family members.

In fact, at this prepubertal age, we have to consider that boys are more concerned than girls to appear older. This is confirmed by the affirmative answer to the question: "Do people smoke because it makes them look older, interesting and important?". Thirty five percent of "active smokers" (compared with only $7 \%$ of "nonsmokers") answered "yes" to this question and the $78 \%$ of those were males (data not shown).

"Active smokers" also tended to live in more crowded homes, without central heating, and with a lower standard of living (although these relationships did not reach statistical significance).

Table 2 shows the relationship between number of cigarettes smoked in the household and percentage of subjects with detectable salivary cotinine measured during the winter period. Frequency of detectable cotinine both in "nonsmokers" and "active smokers" was significantly correlated with the number of cigarettes smoked by household members $(p<0.0001)$. However, for any level of smoking by parents, detectable cotinine was more likely to be found in "active smokers" than in "nonsmokers" ( $\mathrm{p}=0.006$ by logistic regression, odds ratio $(\mathrm{OR})=2.56$ after adjustment for sex, heating and housing). A similar result was obtained when households were subdivided according to the number of smokers present (data not shown).

We also studied (table 3) the relationship between salivary cotinine and the place where the household members smoked while they were at home (specifically, if they smoked $>4$ cigarettes $\cdot$ day $^{-1}$ "at the dinner table" or "in the television room after dinner"). When the household members smoked "at the dinner table" and "in the television room after dinner" the proportion of subjects with detectable cotinine was $75 \%$ in "nonsmokers" and $88 \%$ in "active smokers" $(\mathrm{p}<0.0003$ and $\mathrm{p}<0.001$, respectively). However, for any smoking behaviour by household members, detectable cotinine was more likely to be found in "active smokers" ( $\mathrm{p}<0.001, \mathrm{OR}=2.05$ adjusted for sex, housing and heating).

Table 4 shows the differences between salivary cotinine measured during the winter period and during the spring. Between the winter and spring period the proportion of subjects with detectable cotinine decreased from $21 \%$ to $6 \%$ in "nonsmokers" $(\mathrm{p}<0.04)$. We found no differences in "active smokers" (from 47 to 41; NS).

Table 4. - Differences between salivary cotinine measured during winter period and during spring

\begin{tabular}{lrrrrr}
\hline & \multicolumn{3}{c}{$\begin{array}{c}\text { Percentage of subjects } \\
\text { with detectable cotinine }\end{array}$} & \\
\cline { 2 - 4 } & \multicolumn{2}{c}{ Winter* } & Spring & p \\
\hline "Nonsmokers" & $\%$ & 26 & $(21)$ & 6 & $<0.04$ \\
Total n & 109 & & 52 & \\
"Active smokers" & $\%$ & 54 & $(47)$ & 41 & NS \\
Total n & 37 & & 17 &
\end{tabular}

*: the percentage of subjects who repeated the test during spring is shown in parenthesis.

Table 3. - Relationship between cotinine and smoking behaviour in household (measured during winter period)

\begin{tabular}{|c|c|c|c|c|c|}
\hline & \multicolumn{4}{|c|}{ Smoking behaviour in household } & \multirow[b]{2}{*}{$\mathrm{p}$} \\
\hline & None & $\begin{array}{l}\text { No smoking } \\
\text { at dinner } \\
\text { and } \\
\text { in television } \\
\text { room }\end{array}$ & $\begin{array}{c}\text { Smoking } \\
\text { at dinner } \\
\text { or } \\
\text { in television } \\
\text { room }\end{array}$ & $\begin{array}{l}\text { Smoking } \\
\text { at dinner } \\
\text { and } \\
\text { in television } \\
\text { room }\end{array}$ & \\
\hline \multicolumn{6}{|l|}{ "Nonsmokers" } \\
\hline Subjects with cotinine $\%$ & 14 & 25 & 38 & 75 & $<0.0003$ \\
\hline Concentration $^{\dagger *} \mathrm{ng} \cdot \mathrm{ml}^{-1}$ & 0.66 & 0.93 & 1.21 & 2.33 & $<0.0003$ \\
\hline $\begin{array}{l}\text { Total n } \\
\text { "Active smokers" }\end{array}$ & 56 & 24 & 21 & 8 & \\
\hline Subjects with cotinine $\%$ & 23 & 50 & 70 & 88 & $<0.0011$ \\
\hline Concentration $^{\dagger *} \mathrm{ng} \cdot \mathrm{ml}^{-1}$ & 0.78 & 2.17 & 3.38 & 4.00 & $<0.0011$ \\
\hline Total n & 13 & 6 & 10 & 8 & \\
\hline
\end{tabular}

: geometric mean data from all subjects in group; *: undetectable cotinine concentrations were recorded as $0.5 \mathrm{ng} \cdot \mathrm{ml}^{-1}$. 


\section{Discussion}

Our study was based on questionnaires administered both to parents and children, and on repeated measurements of saliva cotinine levels in a randomly selected sample of children aged 9-14 yrs and living in an Italian semi-rural environment.

We demonstrated that: 1) even at that age, the magnitude of exposure to tobacco smoke is significantly influenced by personal active smoking habit; 2) for both "actively smoking" and "nonsmoking" children, cotinine levels are linked not only to the number of cigarettes smoked but also to the household smoking behaviour; and 3) during spring saliva cotinine is heavily reduced in "nonsmoking" children.

The possibility of measuring cotinine in body fluids allows epidemiologists to objectively measure the exposure to tobacco smoke, previously evaluated only indirectly by means of complex questionnaires. However, as could probably be anticipated, the practice demonstrated that cotinine levels themselves need an explanation: probably even more complex questionnaires will be needed to understand the source of detectable cotinine. Our study was an assay to interpret the personal ETS exposure linking cotinine determinations to questionnaires designed to detect the sources of exposure. We were dealing with an age in which "active smoking" can significantly contribute to cotinine from passive smoking: the latter can derive from household but also from outdoor sources.

Our data show that even a confidential questionnaire cannot be considered as a gold standard for determining the existence of a personal active smoking habit. The admission by the subject that he/she "ever tried some cigarettes" was in our material the best parameter to separate active from nonsmokers, and in all analyses these two groups could be demonstrated to have different cotinine levels, especially during the warm season when cotinine can only practically be detected in "active smokers". However, the label "active smokers" is, to a large extent, a nonspecific parameter, because $33-77 \%$ of the "active smokers" (depending on parent smoking habit) had no detectable cotinine, and it is also relatively insensitive, because at least six children (5\%) in our study, who denied active smoking, had cotinine levels too high for passive exposure.

It is noticeable that "active smokers" are more likely to belong to smoking families, especially if parents do not refrain from smoking at the dinner table or in the television room. It appears that parental smoking is considered an official example, which has profound educational implications and initiates an imitative attitude in childen, causing them to adopt the habit of more or less intensive active smoking at an early age. Also "active smokers" are more frequently males; in apparent contrast with data reported in Italy and in most of Western countries where adolescent females smoke more than males [18].

Questionnaires directed at determining the number of cigarettes smoked daily in the house (not to mention those that ask only about the number of smokers among parents, housekeeper or others) are largely nonspecific and nonsensitive. We introduced a question about parents' smoking behaviour at home (i.e. during and after dinner, in the television room) and demonstrated that this parameter significantly decreased the number of false negatives, i.e. children belonging to smoking families with no detectable cotinine in their saliva). This is particularly true for nonsmoking children living in families where 1-39 cigarettes are smoked daily. If parents smoke during dinner and in television room, $80 \%$ of these children have detectable cotinine levels, whilst only $20 \%$ have cotinine in the absence of this habit. By contrast, when children are "active smokers" or when familial cigarette consumption is heavy (more than 40 cigarettes $\cdot$ day $^{-1}$ ), smoking at dinner and in the television room is less powerful to predict the presence or absence of detectable cotinine.

It must be recognized that this subject is very difficult to deal with. Some questions included in our questionnaire (e.g. "Do you smoke in the presence of the child in the afternoon when he/she performs his/her duties?") were found to be inadequate for predicting detectable cotinine, whilst many others, such as those exploring ETS exposure in public places, at school, etc., could not be included in this study for simplicity. More extensive investigations in this area could certainly help to determine the meaning of detectable cotinine, especially in those children (14\%) who have significant levels of cotinine even though living in nonsmoking families and who deny being "active smokers".

The fact that in our environment the warm season can almost completely abolish smoking exposure demonstrates that climatic conditions are important components of the "life exposure story". The seasonal effect on salivary cotinine concentration was investigated by Cook et al. [19], who found no significant changes between winter and summer determination in 10 towns in England and Wales. In another study [20], however a halving effect of the warmer season on cotinine salivary concentration was reported, but figures and statistical significance were not given.

Previously, other authors have attributed findings concerning passive smoking to climate. For example, TAGER et al. [21] explained the negative effect of maternal cigarette smoking on children's lung function found in East Boston but not in Tucson by means of different climatic situations in the two environments. MurRAY and MORRISON [12] reported a significant increase in the severity of bronchial obstruction and hyperresponsiveness in school-age children with a diagnosis of asthma who were exposed to ETS, when compared to nonexposed subjects. However, they found that these effects were only seen during the cold wet season in Vancouver (Canada) and that no effects were seen during summer.

Therefore, when measuring the health consequences of ETS, one should take into consideration the climate and its influence on the ventilation of houses. This in its turn can also depend on socioeconomic characteristics of the population, crowding index, architecture of the buildings (e.g. one or two floors), etc.

In conclusion, we have found that the salivary cotinine 
concentration is a reliable indicator of exposure to ETS. Whatever action one would like to take in order to prevent this exposure, one should take into consideration the causative factors: our results indicate that personal "active smoking", household smoking behaviour and home ventilation are almost equivalent contributors to cotinine presence in children aged 9-14 yrs. Repeated measures of salivary cotinine cannot only determine the true history of personal exposure, and so precisely predict the health consequences of such contamination, but can also represent a means for active preventive intervention in repeatedly or heavily exposed children. For this purpose, confidential and family questionnaires are at present the only available means to determine the most probable sources of detected cotinine.

\section{References}

1. US Department of Health and Human Services. The health consequences of involuntary smoking: a report of the Surgeon General. Washington, DC, US Government Printing Office, 1986.

2. Fielding JE, Phenow KJ. Health effects of involuntary smoking. N Engl J Med 1988; 319: 1452-1460.

3. Ronchetti R, Martinez FD, Macri' F, et al. Increased serum immunoglobulin ( $\mathrm{IgE}$ ) and increased prevalence of eosinophilia in 9 year old children of smoking parents. J Allergy Clin Immunol 1990; 86: 400-407.

4. Ronchetti R, Bonci E, Cutrera R, et al. Enhanced allergic sensitization related to parental smoking. Arch Dis Child 1992; 67: 496-500.

5. Martinez F, Antognoni G, Macri' F, et al. Parental smoking enhances bronchial responsiveness in nine year old children. Am Rev Respir Dis 1988; 138: 518-523.

6. Martinez FD, Cline M, Burrows B. Increased incidence of asthma in children of smoking mothers. Pediatrics 1992; 89: 21-26.

7. Weitzman M, Gortmaker S, Walker DK, Sobol A. Maternal smoking and childhood asthma. Pediatrics 1990; 85: 505-511.

8. Wright AL, Holberg C, Martinez FD, Taussig LM. The relationship of parental smoking to wheezing and nonwheezing lower respiratory tract illnesses in infancy. J Pediatr 1990; 118: 207-214.
9. Ehrlich R, Kattan M, Godbold J, et al. Childhood asthma and passive smoking. Urinary cotinine as a biomarker of exposure. Am Rev Respir Dis 1992; 145: 594-599.

10. Schilling RSF, Letai AD, Hui SL, Beck GJ, Schoenberg JB, Bouhuys A. Lung function, respiratory disease and smoking in families. Am J Epidemiol 1977; 106: 274-283.

11. Lebowitz MD, Armet DB, Knudson R. The effect of passive smoking on pulmonary function in children. Environ Int 1982; 8: 371-373.

12. Murray AB, Morrison BJ. Passive smoking and the seasonal difference of severity of asthma in children. Chest 1988; 94: 701-708.

13. Greenberg RA, Bauman KE, Strecher VJ, et al. Passive smoking during the first year of life. Am J Public Health 1991; 81: 850-853.

14. Strachan DP, Jarvis MJ, Feyerabend C. Passive smoking, salivary cotinine concentrations, and middle ear effusion in 7 year old children. $\mathrm{Br}$ Med $J$ 1989; 298: $1549-1552$.

15. Langone J, Gjika HB, Van Vunakis H. Nicotine and its metabolites: radioimmunoassay for nicotine and cotinine. Biochem 1973; 12: 5025-5030.

16. Jarvis MJ, Russell MAH, Benowitz NL, Feyerabend C. Elimination of cotinine from body fluids: implications for noninvasive measurement of tobacco smoke exposure. Am J Public Health 1988; 78: 696-698.

17. Norusis MJ. SPSS PC+ Advanced Statistics. 1st Edn. Chicago, SPSS Inc., 1986.

18. Geizerova H, Masironi R. Cigarette smoking in children and adolescents: world review. Proceedings of the World Conference on Smoking and Health, Tokyo, 9-12 November, 1987; p. 601.

19. Cook DG, Whincup PH, Papacosta O, Strachan DP, Jarvis MJ, Bryant A. Relation of passive smoking as assessed by salivary cotinine concentration and questionnaires to spirometric indices in children. Thorax 1993; 48: 14-20.

20. Strachan DP, Jarvis M, Feyerabend C. Letter. Br Med J 1989; 299: 259.

21. Tager IB, Segal MR, Munoz A, Weiss ST, Speizer FE. The effect of maternal cigarette smoking on the pulmonary function of children and adolescents. Analyses of data from two populations. Am Rev Respir Dis 1987; 138: $1366-1370$. 